\title{
Hydraulic conductivity and low-density lipoprotein transport of the venous graft wall in an arterial bypass
}

\author{
Zhenze Wang ${ }^{1 \dagger}$, Ming Liu ${ }^{2,3 \dagger}$, Xiao Liu ${ }^{2,3}$, Anqiang Sun ${ }^{2,3^{*}}$, Yubo Fan ${ }^{1,2,3^{*}}$ and Xiaoyan Deng ${ }^{2,3}$
}

${ }^{*}$ Correspondence:
saq@buaa.edu.cn;
yubofan@buaa.edu.cn
${ }^{+}$Zhenze Wang and Ming
Liu contributed equally to
this work and should be
considered co-first authors
${ }^{2}$ Key Laboratory
for Biomechanics
and Mechanobiology
of Ministry of Education,
School of Biological Science
and Medical Engineering,
Beihang University,
Beijing 100083, China
Full list of author information
is available at the end of the
article

*Correspondence: yubofan@buaa.edu.cn †'Zhenze Wang and Ming Liu contributed equally to this work and should be considered co-first authors

and Mechanobiology of Ministry of Education, Full list of author information article

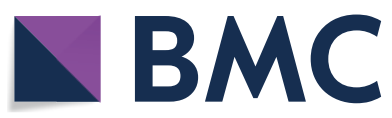

(c) The Author(s) 2019. This article is distributed under the terms of the Creative Commons Attribution 4.0 International License (http://creativecommons.org/licenses/by/4.0/), which permits unrestricted use, distribution, and reproduction in any medium, provided you give appropriate credit to the original author(s) and the source, provide a link to the Creative Commons license, and indicate if changes were made. The Creative Commons Public Domain Dedication waiver (http://creativecommons.org/publi cdomain/zero/1.0/) applies to the data made available in this article, unless otherwise stated.

\begin{abstract}
Background: Blood flow condition may have influence upon the hydraulic conductivity of venous graft $\left(L_{p, v e i n}\right)$ in an arterial bypass, then affecting the accumulation of low-density lipoproteins (LDLs) within the graft wall. To probe this possibility, we first measured in vitro the filtration rates of swine lateral saphenous vein segments under different flow rates, and the correlation of $L_{p, v e i n}$ with wall shear stress (WSS) was then obtained.

Results: The experimental results showed that when WSS was very low, $L_{p, \text { vein }}$ would increase drastically with WSS from $1.16 \pm 0.15 \times 10^{-11} \mathrm{~m} / \mathrm{s}$ Pa at 0 dyn $/ \mathrm{cm}^{2}$ to $2.17 \pm 0.20 \times 10^{-11} \mathrm{~m} / \mathrm{s}$ Pa at $0.7 \mathrm{dyn} / \mathrm{cm}^{2}$, then became constant of approximately $2.33 \times 10^{-11} \mathrm{~m} / \mathrm{s}$ Pa as the WSS increased further. Based on the experimental results, we assumed three different cases of $L_{p, v e i n}$ and numerically simulated the LDLs transport in an arterial bypass model with venous graft. Case $A: L_{p, v e i n}=2.33 \times 10^{-11} \mathrm{~m} / \mathrm{s} P$; Case $B: L_{p, v e i n}=1.16 \times 10^{-11} \mathrm{~m} / \mathrm{s}$ Pa (static condition with WSS of 0 ); Case $C: L_{p, v e i n}$ was shear dependent. The simulation showed that the deposition/accumulation of LDLs within the venous graft wall in Case A was greatly enhanced when compared with that in Case B. However, the LDL accumulation in the graft wall was similar for Case A and Case C.

Conclusions: Our study, therefore, indicates that when the venous graft was implanted as a bypass graft, the $L_{\text {p,vein }}$ might remain nearly constant along its whole length except for very few areas where the value of WSS was extremely low (less than $0.7 \mathrm{dyn} / \mathrm{cm}^{2}$ ) and the effects of $L_{p, v e i n}$ modulated by blood flow on LDL transport may be neglected.
\end{abstract}

Keywords: Venous graft, Low-density lipoprotein, Hydraulic conductivity, Wall shear stress

\section{Introduction}

Autogenous vein (e.g., the greater saphenous vein) segments are widely used in vascular bypass surgery to relieve arterial occlusion. Nevertheless, when implanted into the arterial system as grafts, veins will develop a rapidly progressive and structurally diffusive form of atherosclerotic lesions which has been termed as "accelerated atherosclerosis" $[1-4]$, and this has become the major cause of venous graft late failure $[5,6]$. 
The mechanism of the accelerated atherogenesis in venous grafts has been studied extensively [3, 7]. It is well documented that the process of atherogenesis in venous grafts is very similar to the one in the arterial system, in which the deposition/accumulation of lipids such as low-density lipoproteins (LDLs) within the arterial wall is the initial event, and the high LDL concentration within the vessel wall could accelerate the atherogenesis [8].

From the viewpoint of mass transport, the hydraulic conductivity of blood vessel walls may play an important role in the accumulation of LDLs and atherosclerotic lesion development in the venous graft. In our previous study [9], we measured hydraulic conductivity of the swine lateral saphenous vein in vitro. Using the measured data, we numerically analyzed the transport of LDLs in the venous graft. Our result demonstrated that hydraulic conductivity of the venous graft was significantly higher than that of the host artery. High hydraulic conductivity could not only elevate concentration polarization of LDLs at the luminal surface of the venous graft, and then enhancing the transport of LDLs into the venous graft wall by the mechanism of concentration gradient, but also could directly lead to high influx of LDLs into the vessel wall by convective flow. As a result, LDLs would accumulate rapidly within the wall of the venous graft, in turn accelerating the genesis and development of atherosclerosis in the venous grafts.

The hydraulic conductivity of arteries and cultured endothelial cells has shown to be greatly affected by fluid flow [10]. For instance, using bovine aortic endothelial cell (BAEC) monolayers, Sill et al. [11] observed that fluid flow could cause an increase in hydraulic conductivity when compared to that in the absence of flow. Lever et al. found approximately $30 \%$ increase in hydraulic conductivity of the rabbit common carotid artery when the flow rate was increased from zero to a level of $10 \mathrm{~mL} / \mathrm{min}$ [12]. However, there is a paucity of investigations on the effect of flow conditions on the hydraulic conductivity of the vein.

Since flow conditions may also affect the hydraulic conductivities of the venous graft $\left(L_{\mathrm{p}, \mathrm{vein}}\right)$, in turn affecting LDL deposition/accumulation within the graft wall, in the present article, we measured in vitro the filtration rates of the swine lateral saphenous vein under different wall shear stress (WSS), from which the correlation of $L_{\mathrm{p}, \text { vein }}$ with wall shear stress was derived. We then numerically simulated LDL transport in a two-dimensional bypass model with a venous graft and analyzed the deposition and accumulation of LDLs within the wall of venous graft.

\section{Methods}

Measurement of filtration rates under different WSS for venous wall Preparation of vessel segments

The lateral saphenous veins obtained from farm swine were used for the study. Experiments in the present study were approved by the university ethics review board. The specifically designed metal supporting frame was used to fix the 6 - to 7-cm-long segment of blood excised from the swine leg. This procedure of the venous segment preparation for measurements has been described in detail previously [9]. 


\section{Perfusion solution}

For perfusion, freshly prepared albumin Krebs solution was used. Bovine serum albumin (Sigma Chemical Co., St. Louis, MO, USA) was dissolved in the Krebs solution (concentrations in mmol/L: $\mathrm{NaCl}, 118 ; \mathrm{KCl}, 4.7 ; \mathrm{NaHCO}_{3}, 25 ; \mathrm{KH}_{2} \mathrm{PO}_{4}, 1.2 ; \mathrm{MgSO}_{4}, 1.2 ; \mathrm{CaCl}_{2}$, 2.5; glucose, 11 ) at a concentration of $1.0 \mathrm{mg} / \mathrm{mL}$ (density, $1.005 \mathrm{~g} / \mathrm{cm}^{3}$; viscous, $0.0116 \mathrm{~g}$ / $\mathrm{cm} \mathrm{s}$ ). The $\mathrm{pH}$ value of the solution was adjusted to 7.4 .

\section{Experimental procedure}

The harvested vein segment fixed by a metal frame was encased in the stainless steel chamber (Fig. 1a) and connected to the experimental perfusion system (Fig. 1b), in which the upper reservoir could provide a steady flow through the vessel keeping the vessel pressurized at a preset constant pressure. Then the stainless steel chamber was filled with the Krebs solution and covered by a transparent Plexiglas plate. A calibrated capillary was installed on the Plexiglas cover plate with its orifice connecting to the inside of the chamber for measuring the increment of liquid volume within the chamber.

The filtration rate measurements of the vein were carried out under arterial pressure (hydrostatic pressure $100 \mathrm{mmHg}$, transmural pressure $70 \mathrm{mmHg}$ ) [13] with different flow rates, i.e., $0 \mathrm{~mL} / \mathrm{min}, 20 \mathrm{~mL} / \mathrm{min}, 40 \mathrm{~mL} / \mathrm{min}, 60 \mathrm{~mL} / \mathrm{min}, 80 \mathrm{~mL} / \mathrm{min}, 100 \mathrm{~mL} / \mathrm{min}$, $200 \mathrm{~mL} / \mathrm{min}$ and $500 \mathrm{~mL} / \mathrm{min}$. By adjusting the clamp on the outlet tubing connected to the distal end of the test blood vessel, the desired flow rate through the vessel could be obtained.

The filtration rate $\left(v_{\mathrm{w}}\right)$ across the test vessel wall was calculated by the following formula:

$$
v_{\mathrm{w}}=\Delta V / S t \text {, }
$$

where $\Delta V$ is the liquid volume between two marked lines on the calibrated capillary, $t$ is the time required for the liquid meniscus rising in the capillary to pass the two marked lines and $S$ is the total area of the outer surface of the test vessel.

Based on the $v_{\mathrm{w}}$, we could obtain the $L_{\mathrm{p} \text {,vein }}$ using Darcy's law:

$$
L_{\mathrm{p}, \mathrm{vein}}=V_{\mathrm{w}} / \Delta p \text {. }
$$

The wall shear stress $\left(\boldsymbol{\tau}_{\mathrm{w}}\right)$ acting on the luminal surface of the test vessel was given by

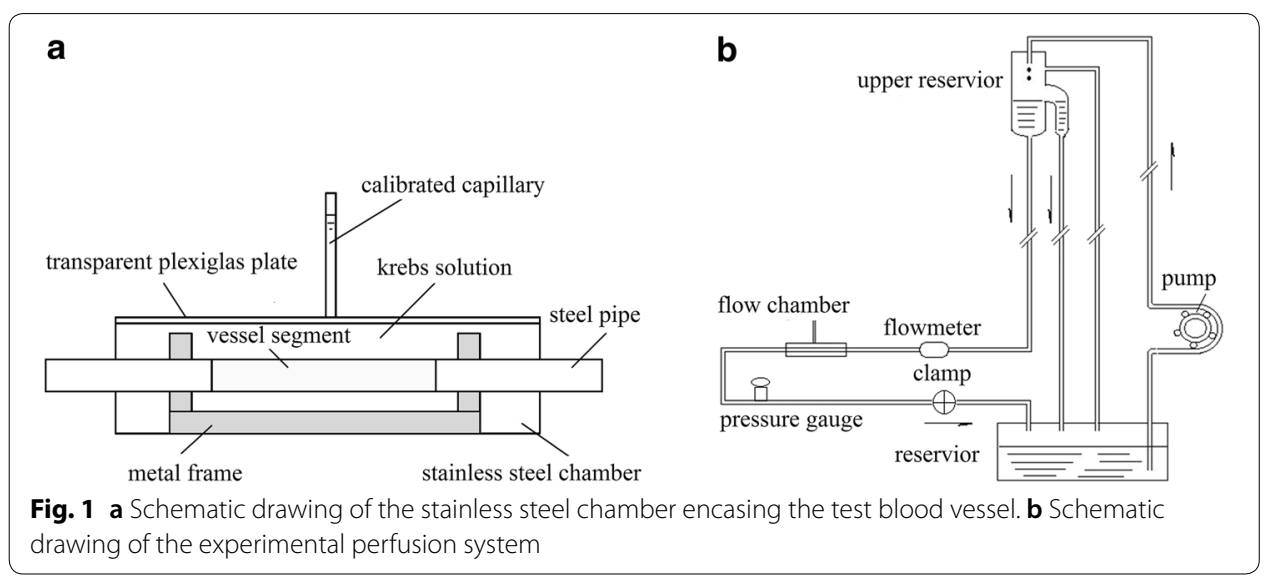




$$
\boldsymbol{\tau}_{\mathrm{w}}=4 \mu Q /\left(\pi R^{3}\right)
$$

where $\mu$ and $R$ represent, respectively, the viscosity of perfusion solution and the internal radius of the test vessel. $Q$ is the flow rate through the test vessel.

Each experiment with a given flow rate was repeated three times and all experiments were carried out at a room temperature of $23 \pm 0.5^{\circ} \mathrm{C}$. During the perfusing process, the length and external diameter of the vessel were measured for calculating the total area $S$ of the vessel. With finishing each experiment turn, the test vessel was fixed at the test hemodynamics condition by perfusing with $10 \%$ formalin solution overnight to obtain the histological cross sections of the vessel, from which the internal radius $R$ of the test vessel could be established.

\section{Statistical analysis}

SPSS19.0 (SPSS Inc.) software was applied for statistical analysis. All experiment results were expressed as mean \pm standard deviation (SD). One-way ANOVA was used to compare mean values of the experiment data. Differences were considered significant when $P<0.05$.

\section{Numerical simulation of LDL transport}

\section{Geometric model}

Simplified bypass models (two dimensional) with $80 \%$ area occluded in the host artery were adopted in this simulation, as shown in Fig. 2. In the calculated model, both the host artery wall and the venous graft wall were treated as a single-layer porous medium with an endothelium layer. $\Gamma_{\text {adv }}$ was the interface between the media and adventitia. The outer diameter of the host artery $\left(D_{\mathrm{a}}\right)$ and the thickness of arterial wall $\left(h_{\mathrm{a}}\right)$ were set to be 5.2 and $0.35 \mathrm{~mm}$, respectively. The venous graft's outer diameter and thickness $\left(D_{\mathrm{v}}\right.$ and $h_{\mathrm{v}}$ ) were, respectively, 6.2 and $0.035 \mathrm{~mm}$. The anastomosis angle was $45^{\circ}$. The host artery was $80 \%$ area occluded at the middle between points B and C.

\section{Governing equations}

To model bulk blood flow in the lumen and transmural flow in the endothelium layer, Navier-Stokes equations and Darcy's law were employed, respectively. For modeling of mass balance, the convection-diffusion equation was employed in the lumen. To form a

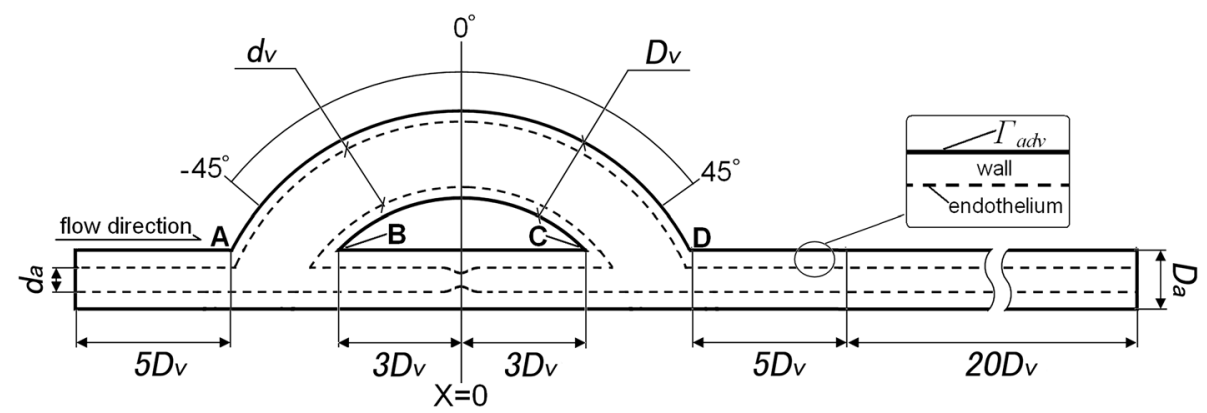

Fig. 2 Schematic illustration of the bypass model with venous graft used in the simulations 
convection-diffusion-reaction equation in the endothelium layer, additional reaction term was added. Furthermore, the Kedem-Katchalsky equations were employed to couple the fluid dynamics and mass balance at membranes, i.e., endothelium.

Fluid flow dynamics Blood flow in the vessel lumen was simulated by the steady-state incompressible Navier-Stokes and continuity equations [14]:

$$
\begin{aligned}
& \rho(\boldsymbol{u} \cdot \nabla) \boldsymbol{u}+\nabla p-\mu \Delta \boldsymbol{u}=\mathbf{0}, \\
& \nabla \cdot \boldsymbol{u}=\mathbf{0},
\end{aligned}
$$

where $\boldsymbol{u}$ and $p$, respectively, represent fluid velocity vector and pressure. $\rho$ and $\mu$ are the density $\left(\rho=1050 \mathrm{~kg} / \mathrm{m}^{3}\right)$ and the viscosity of blood $\left(\mu=3.5 \times 10^{-3} \mathrm{~kg} / \mathrm{m} \mathrm{s}\right)$, respectively [15]

The transmural fluid flow across the endothelium $\left(J_{\mathrm{v}}\right)$ was modeled by the Kedem-Katchalsky equation [16]:

$$
J_{\mathrm{v}}=L_{\text {pend }}(\Delta p-\sigma \Delta \pi),
$$

where $\Delta p$ and $\Delta \pi$ are the hydraulic pressure and osmotic pressure differences across the endothelium; $\sigma$ and $L_{\text {pend }}$, respectively, represent the osmotic reflection coefficient and the hydraulic conductivity of the endothelium. In the present simulation, $\Delta \pi$ was neglected because the influence of osmotic pressure on the fluid dynamics is too small, compared to hydraulic pressure.

The transmural fluid flow across the arterial wall and venous wall was modeled by Darcy's law.

In a homogeneously permeable medium, Darcy's law can be described as a simple proportional relationship between the instantaneous flow rate through a porous medium of permeability, the dynamic viscosity of the fluid and the pressure drop over a given distance. From the viewpoint of mass transport, Darcy's law can be used to describe the hydraulic conductivity of blood vessel walls when the blood flow remains stable, laminar:

$$
\frac{\mu_{\mathrm{w}}}{\mathrm{K}_{\mathrm{w}}} \boldsymbol{u}_{\mathrm{w}}=-\nabla\left(p_{\mathrm{w}}\right)
$$

and continuity equation

$$
\nabla \cdot \boldsymbol{u}_{\mathrm{w}}=\mathbf{0},
$$

where $\boldsymbol{u}_{\mathrm{w}}$ and $\boldsymbol{p}_{\mathrm{w}}$ represent, respectively, the velocity vector and pressure in the vessel wall, $K_{\mathrm{w}}$ is the hydraulic permeability of the wall and $\mu_{\mathrm{w}}$ is the viscosity of plasma.

Mass transport The transport of LDLs in the vessel lumen was modeled by the convection-diffusion equation as follows [17]:

$$
\nabla \cdot(-D \nabla c+c \boldsymbol{u})=\mathbf{0},
$$

where $c$ represents the concentration of LDLs in the lumen, and $D$ is the diffusion coefficient of LDLs in blood, $D=5.898 \times 10^{-12} \mathrm{~m}^{2} / \mathrm{s}$ [18].

The flux of LDLs across the endothelium $\left(J_{\mathrm{s}}\right)$ was described by the following equation [17]:

$$
J_{\mathrm{s}}=P_{\mathrm{end}} \Delta c+\left(1-\sigma_{\mathrm{f}}\right) J_{\mathrm{v}} \bar{c},
$$


where $\Delta c$ is LDL concentration difference across the endothelium, $P_{\text {end }}$ is the endothelial permeability to LDLs and $\bar{c}$ is the mean concentration of LDLs in the endothelium. $\sigma_{\mathrm{f}}$ is the solvent reflection coefficient.

The transport of LDLs within the vessel wall was modeled by the convection-diffusion-reaction equation as follows [19]:

$$
\nabla \cdot\left(-D_{\mathrm{w}} \nabla c_{\mathrm{w}}+K_{\mathrm{lag}} c_{\mathrm{w}} \boldsymbol{u}_{\mathrm{w}}\right)=r_{\mathrm{w}} c_{\mathrm{w}}
$$

where $c_{\mathrm{w}}$ and $D_{\mathrm{w}}$, respectively, represent the concentration of LDLs within vessel wall and the effective diffusivity of LDLs in the wall, $r_{\mathrm{w}}$ is the chemical reaction rate, and $K_{\text {lag }}$ is the LDLs lag coefficient.

\section{Boundary conditions}

Boundary conditions for blood flow simulation A fully developed (parabolic) velocity profile with a mean velocity of $0.22 \mathrm{~m} / \mathrm{s}$ was applied at the inlet of the arterial lumen so that Reynolds number $(R e)$ based on the internal diameter of the host artery was 300 . At the outlet of arterial lumen, the pressure $p$ was set at $100 \mathrm{mmHg}$. At the lumen side of the endothelial boundary, a wall to lumen transmural fluid velocity was prescribed by

$$
\boldsymbol{u} \cdot \boldsymbol{n}_{\mathrm{l}}=J_{\mathrm{v}} \cdot
$$

At the wall side of the endothelial boundary, a lumen-to-wall transmural velocity was prescribed by

$$
\boldsymbol{u}_{\mathrm{w}} \cdot \boldsymbol{n}_{\mathrm{w}}=-J_{\mathrm{v}},
$$

where $\boldsymbol{n}_{1}$ and $\boldsymbol{n}_{\mathrm{w}}$ represent the out normal vectors of the lumen sub-domain and wall sub-domain, respectively. $J_{\mathrm{v}}$ is the transmural fluid velocity across the endothelium.

A constant pressure boundary condition of $30 \mathrm{mmHg}$ was prescribed at the media-adventitia interface $\left(\Gamma_{\text {adv }}\right)$ [19].

At the occlusion of the host arterial lumen:

$$
\boldsymbol{u}=0 .
$$

No flow was assumed for all other boundaries.

Boundary conditions for LDL transport The inflow concentration of LDLs $\left(c_{0}\right)$ at the lumen inlet boundary was taken as $28.6 \times 10^{-3} \mathrm{nmol} / \mathrm{mm}^{3}$ [20]. At the occlusion of the arterial lumen, the flux of LDLs in the normal direction of the lumen domain was set at 0 . At the lumen side of the endothelial boundary, a wall to lumen flux of LDLs was prescribed by

$$
-D \nabla c \boldsymbol{n}_{1}+\boldsymbol{u} c \boldsymbol{n}_{1}=J_{\mathrm{s}} .
$$

At the wall side of the endothelial boundary, a lumen-to-wall flux of LDLs was prescribed by

$$
-D_{\mathrm{w}} \nabla c_{\mathrm{w}} \boldsymbol{n}_{\mathrm{w}}+\boldsymbol{u}_{\mathrm{w}} c_{\mathrm{w}} \boldsymbol{n}_{\mathrm{w}}=-J_{\mathrm{s}} .
$$

For other boundaries, the concentration gradient of LDLs in the boundary normal direction was assumed to be zero. 


\section{Parameters}

To solve the governing equations, we need to acquire the values of seven parameters, namely the hydraulic permeability of subendothelial wall $\left(K_{\mathrm{w}}\right)$, the hydraulic conductivity of endothelium $\left(L_{\text {pend }}\right)$, the solvent reflection coefficient $\left(\sigma_{\mathrm{f}}\right)$, the endothelial permeability $\left(P_{\text {end }}\right)$ to LDLs, the chemical reaction rate $\left(r_{\mathrm{w}}\right)$, the effective diffusivity of LDLs in the subendothelial layer $\left(D_{\mathrm{w}}\right)$ and the solute lag coefficient $\left(K_{\mathrm{lag}}\right)$.

Host artery All the parameters were adopted in the literature, which are presented in Table 1.

Venous graft The hydraulic conductivity of the venous wall $\left(L_{\mathrm{p}, \text { vein }}\right)$, hydraulic conductivity of the venous endothelium $\left(L_{\text {pend,vein }}\right)$ and hydraulic conductivity of the subendothelial wall of the vein $\left(L_{\mathrm{pw}, \text { vein }}\right)$ were assumed to have the relation below [21]:

$$
\frac{1}{L_{\mathrm{p}, \text { vein }}}=\frac{1}{L_{\mathrm{pend}, \text { vein }}}+\frac{1}{L_{\mathrm{pw}, \text { vein }}},
$$

where $L_{\mathrm{p}, \mathrm{vein}}=V_{\mathrm{w}} / \Delta p$, which could be obtained from the results of "Measurement of filtration rate for venous wall". We assumed that the $L_{\mathrm{pw}, \mathrm{vein}}$ was 4 folder of $L_{\mathrm{pend}}$ vein when

Table 1 Values of parameters used in the simulation

\begin{tabular}{|c|c|c|}
\hline Symbol & Description & Value, units \\
\hline$D_{v}$ & Outer diameter of venous graft [9] & $6.2 \mathrm{~mm}$ \\
\hline$d_{v}$ & Internal diameter of venous graft [9] & $6.13 \mathrm{~mm}$ \\
\hline$h_{v}$ & Thickness of venous wall [9] & $0.035 \mathrm{~mm}$ \\
\hline$D_{a}$ & Outer diameter of host artery [9] & $5.2 \mathrm{~mm}$ \\
\hline$d_{\mathrm{a}}$ & Internal diameter of host artery [9] & $4.5 \mathrm{~mm}$ \\
\hline$h_{\mathrm{a}}$ & Thickness of arterial wall [9] & $0.35 \mathrm{~mm}$ \\
\hline$P$ & Density of blood [15] & $1050 \mathrm{~kg} / \mathrm{m}^{3}$ \\
\hline$\mu$ & Viscosity of blood [15] & $3.5 \times 10^{-3} \mathrm{~kg} / \mathrm{m} \mathrm{s}$ \\
\hline$L_{\text {pend,artery }}$ & Hydraulic conductivity of arterial endothelium & $3.5551 \times 10^{-12} \mathrm{~m} / \mathrm{s} \mathrm{Pa}$ \\
\hline \multirow[t]{4}{*}{$L_{\text {pend,vein }}$} & Hydraulic conductivity of venous endothelium & \\
\hline & Case A: $3.9091 \times 10^{-11} \mathrm{~m} / \mathrm{s} \mathrm{Pa}$ & \\
\hline & Case B: $1.4457 \times 10^{-11} \mathrm{~m} / \mathrm{s} \mathrm{Pa}$ & \\
\hline & Case C: $\left(2.522 \times 10^{-11}\right) \times$ WSS $^{(1 / 10)}+1.532 \times 10^{-11}$ & \\
\hline$\mu_{\mathrm{w} \text {, artery }}$ & Viscosity of plasma in arterial wall [23] & $0.72 \times 10^{-3} \mathrm{~kg} / \mathrm{m} \mathrm{s}$ \\
\hline$\mu_{\mathrm{w} \text {, vein }}$ & Viscosity of plasma in venous wall [23] & $0.72 \times 10^{-3} \mathrm{~kg} / \mathrm{m} \mathrm{s}$ \\
\hline$K_{\mathrm{w}, \text { artery }}$ & Hydraulic permeability of subendothelial wall of artery & $1.3438 \times 10^{-18} \mathrm{~m}^{2}$ \\
\hline$K_{\mathrm{w} \text {, vein }}$ & Hydraulic permeability of subendothelial wall of vein & $1.4572 \times 10^{-18} \mathrm{~m}^{2}$ \\
\hline$D_{1}$ & LDL diffusion coefficient in luminal blood [18] & $5.898 \times 10^{-12} \mathrm{~m}^{2} / \mathrm{s}$ \\
\hline$D_{\mathrm{W}}$ artery & LDL diffusion coefficient in arterial wall $[17,24]$ & $1.42 \times 10^{-12} \mathrm{~m}^{2} / \mathrm{s}$ \\
\hline$D_{W, \text { vein }}$ & LDL diffusion coefficient in venous wall $[17,24]$ & $1.42 \times 10^{-12} \mathrm{~m}^{2} / \mathrm{s}$ \\
\hline$P_{\text {end, artery }}$ & Arterial endothelial permeability $[17,24]$ & $5.21 \times 10^{-10} \mathrm{~m} / \mathrm{s}$ \\
\hline$P_{\text {end, vein }}$ & Venous endothelial permeability $[17,24]$ & $5.21 \times 10^{-10} \mathrm{~m} / \mathrm{s}$ \\
\hline$\sigma_{\mathrm{f} \text {, artery }}$ & Solvent reflection coefficient in arterial wall $[23,25]$ & 0.997 \\
\hline$\sigma_{\mathrm{f}, \text { vein }}$ & Solvent reflection coefficient in venous wall $[23,25]$ & 0.997 \\
\hline Klag, artery & Solute lag coefficient in arterial wall $[17,24]$ & 0.1486 \\
\hline$K_{\text {lag, vein }}$ & Solute lag coefficient in venous wall $[17,24]$ & 0.1486 \\
\hline$r_{\mathrm{w}, \text { artery }}$ & LDL chemical reaction rate in arterial wall $[17,24]$ & $-6.05 \times 10^{-4} s^{-1}$ \\
\hline$r_{W, \text { vein }}$ & LDL chemical reaction rate in venous wall $[17,24]$ & $-6.05 \times 10^{-4} s^{-1}$ \\
\hline
\end{tabular}


we performed the test experiments on vessels under no flow condition [19], then $L_{\mathrm{pw}, \mathrm{vein}}$ and $L_{\text {pend,vein }}$ under 0 dyn $/ \mathrm{cm}^{2}$ of WSS could be acquired. Assuming that the $L_{\mathrm{pw}, \text { vein }}$ is constant with the flow rate, we could obtain $L_{\text {pend,vein }}$ under other different WSS conditions.

Since $L_{\mathrm{pw}, \mathrm{vein}}=\frac{K_{\mathrm{w}, \text { eein }}}{\mu_{\mathrm{w}, \text { vein }} h_{\mathrm{vein}}}[22]$, and $h_{\mathrm{vein}}$ (the thickness of venous wall) could be obtained from the histological cross sections, we can get the hydraulic permeability of subendothelial wall of vein $\left(K_{\mathrm{w}, \mathrm{vein}}\right)$. We assumed that other parameters of the vein were the same as those of the artery (Table 1$)$.

\section{Computation procedures}

The numerical simulations were carried out using a validated finite elemental algorithm Comsol Multiphysics (COMSOL AB, Sweden). First, the pressure and the velocity fields were obtained by performing flow simulations, the solutions were used later on for the simulations of LDL transport. The threshold value for velocity and continuity residual detection was set to $1.0 \times 10^{-5}$ to ensure the convergence of the calculated results. The numerical results for the flow and the transport of LDLs were determined to be mesh independent. In addition, we validated the mesh independence of results obtained. The criteria of mesh independence were set as the difference of $J_{\mathrm{s}}$ between the meshes used for computations and denser meshes was less than $3 \%$. Based on these criteria, the final computational meshes consisted of 712,620 cubic elements.

\section{Results}

\section{Hydraulic conductivity}

In the present study, we first measured the filtration rates across $\left(V_{\mathrm{w}}\right)$ the walls of the venous segments under different WSS conditions. Then based on the measured data, we derived the correlation of $L_{\text {p,vein }}$ with WSS using Eq. (2). The results are shown in Fig. 3a. It can be seen that when WSS is very low $L_{\mathrm{p}, \text { vein }}$ would increase dramatically from $1.16 \pm 0.15 \times 10^{-11} \mathrm{~m} / \mathrm{s}$ Pa at WSS of 0 to $2.17 \pm 0.20 \times 10^{-11} \mathrm{~m} / \mathrm{s}$ Pa at WSS of $0.7 \mathrm{dyn} /$ $\mathrm{cm}^{2}$. But beyond that $L_{\mathrm{p}, \text { vein }}$ would remain almost constant (approximately $2.33 \times 10^{-11}$ $\mathrm{m} / \mathrm{s} \mathrm{Pa})$.

Based on the values of $L_{\mathrm{p}, \mathrm{vein}}$, we calculated $L_{\mathrm{pend}, \text { vein, }}$, the hydraulic conductivity of the venous endothelium using Eq. (17). The obtained results are shown in Fig. 3b. By curve fitting, it can be shown that $L_{\text {pend,vein }}=2.522 \times 10^{-11} \times \mathrm{WSS}^{0.1}+1.532 \times 10^{-11}$.

\section{Numerical comparison of LDL transport}

Since the experimental measurements showed that when WSS was greater than 0.7 $\mathrm{dyn} / \mathrm{cm}^{2}, L_{\mathrm{p} \text {,vein }}$ would remain almost constant at a value of approximately $2.33 \times 10^{-11}$ $\mathrm{m} / \mathrm{s} \mathrm{Pa}$ and the numerical simulation of blood flow indicated that there were very few areas in the bypass model where WSS would be less than $0.7 \mathrm{dyn} / \mathrm{cm}^{2}$, in the present numerical study, we assumed three cases of $L_{\mathrm{p} \text {,vein }}$ to compute the transport and accumulation of LDLs in the bypass mode. Case A: $L_{\mathrm{p}, \text { vein }}=\mathrm{a}$ constant value of $2.33 \times 10^{-11}$ 

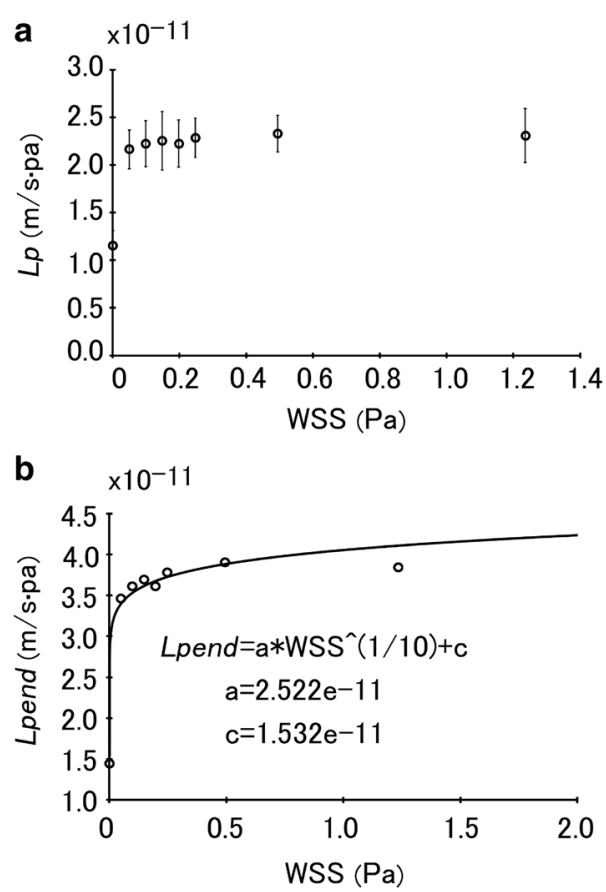

Fig. 3 a Hydraulic conductivities $\left(L_{p, v e i n}\right)$ of the venous segments measured under different wall shear stress conditions. $\mathbf{b}$ Hydraulic conductivities of the endothelium of the venous segments ( $\left.L_{\text {pend,vein }}\right)$ under different wall shear stress conditions

$\mathrm{m} / \mathrm{s}$ Pa; Case B: $L_{\mathrm{p}, \text { vein }}=1.16 \times 10^{-11} \mathrm{~m} / \mathrm{s}$ Pa (static condition with WSS of 0); Case C: $L_{\mathrm{p} \text {,vein }}$ is shear dependent as derived from the experimental measurements.

Figure 4a shows LDL concentration $\left(c_{\mathrm{w}}\right)$ distributions in the middle position of the venous graft wall for the three cases. As evident from the figure, the distribution of $c_{\mathrm{w}}$ for Case $\mathrm{A}$ and Case $\mathrm{C}$ is very similar. However, when compared with Case $\mathrm{B}, c_{\mathrm{w}}$ for Cases $A$ and $C$ is generally higher in most regions of the venous graft wall. Figure $4 \mathrm{~b}$ gives the comparison of $c_{\mathrm{w}}$ among the three cases in terms of percentage difference. It can be seen that the difference between Case A and Case B is prominent. For instance, the percentage difference is more than $10 \%$ in most regions, especially in the exit region of the graft inner wall (line 2-2), where the percentage difference reaches as high as $26 \%$. But for Case A and Case $\mathrm{C}$, there is no evident difference in all regions of the graft. The highest difference in $c_{\mathrm{w}}$ between the two cases is located in the middle section of the outer wall (line 1-1), which is less than $5 \%$.

\section{Effect of arterial stenosis severity on LDL transport}

In clinical practice, the stenosis degree is an important indicator of necessity for bypass surgery. Usually, when the degree of arterial narrowing is greater than $70 \%$, surgical intervention would be eminent. Besides, after the surgery, the stenosis of the host artery would continue to develop, resulting in the alteration of the flow field in the venous graft, which would, in turn, affect the transport of LDLs in the graft. To clarify the impact of stenosis severity on LDL deposition/accumulation within the venous graft wall, we 


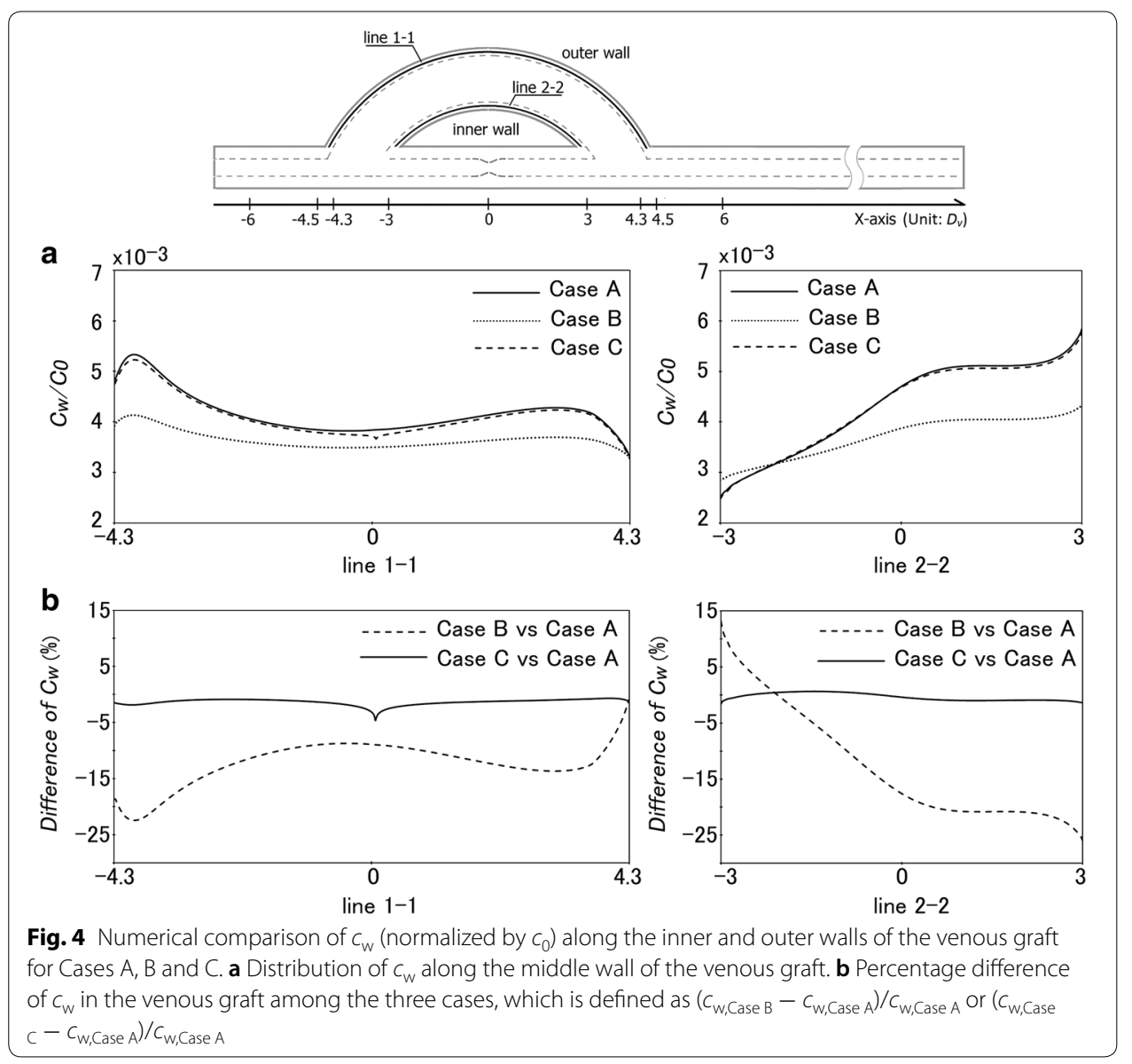

numerically simulated LDL transport in bypass models with different arterial stenosis that has 70, 80 and $90 \%$ reduction in the cross-sectional area of the host artery, using the shear-dependent $L_{\mathrm{p} \text {,vein }}$.

As shown in Fig. 5a, the distributions of $c_{\mathrm{w}}$ along the venous graft have much in common for the three bypass models with different stenoses. Nevertheless, it is still evident that the positions of the local minima of $c_{\mathrm{w}}$, locating at the middle of the graft outer wall, are different. The percentage differences in the $c_{\mathrm{w}}$ for the three models are presented in Fig. 5b. From the figure, it can be seen that there is no significant difference in $c_{\mathrm{w}}$ between the models of 70 and $80 \%$ occlusion. Only when comparing the $90 \%$ model with the $70 \%$ one, the percentage difference is somewhat prominent, the maximum of which is approximately $15 \%$.

\section{Discussion}

The late failure of venous grafts, which is usually caused by accelerated atherogenesis, has long been a common problem that limits the therapy of arterial bypass surgery. We previously demonstrated that enhanced $L_{\mathrm{p} \text {,vein }}$ could lead to fast infiltration/deposition of LDLs within the venous graft wall, and hence the accelerated genesis and development of atherosclerosis [9]. 

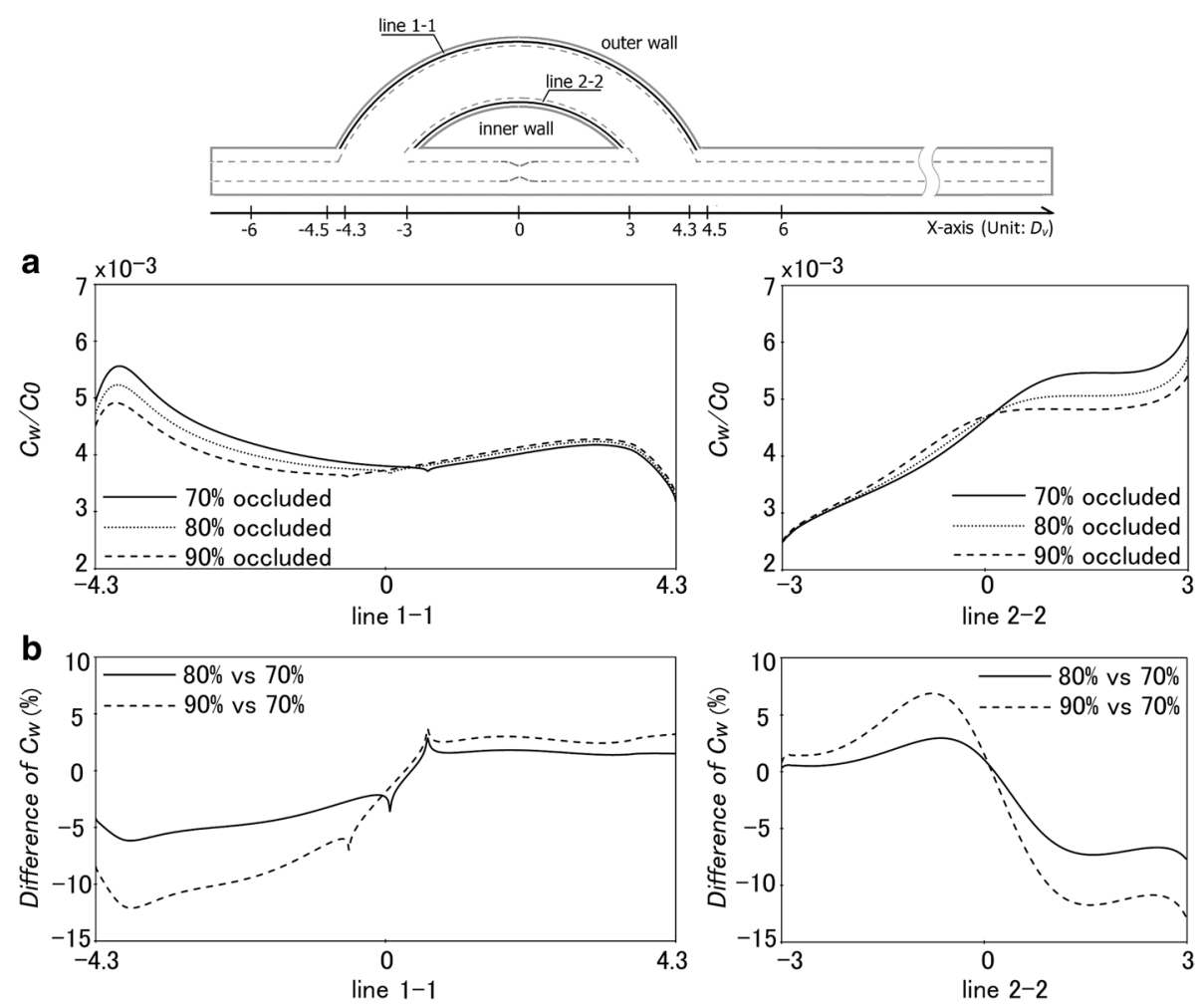

Fig. 5 Numerical results of $c_{w}$ (normalized by $c_{0}$ ) along different lines for cases with stenosis degrees of $70 \%$, $80 \%$ and $90 \%$. a Distribution of $c_{w}$ in the venous graft. b Percentage difference of $c_{w}$ in the venous graft. The percentage difference was defined as $\left(c_{\mathrm{w}, 80 \% \text { occluded }}-c_{\mathrm{w}, 70 \% \text { occluded }}\right) / c_{\mathrm{w}, 70 \% \text { occluded }}$ or $\left(c_{\mathrm{w}, 90 \% \text { occluded }}-c_{\mathrm{w}, 70 \%}\right.$ occluded $) / c_{w, 70 \% \text { occluded }}$

As hydraulic conductivity of blood vessels can be affected by blood flow, in the present study we investigated the effect of $L_{\mathrm{p}, \text { vein }}$ modulated by flow on LDL accumulations within the wall of the venous graft. We first measured the filtration rates of the swine lateral saphenous vein (hence the $L_{\mathrm{p} \text {,vein }}$ ) under different flow/WSS conditions. To our best knowledge, this is the first in vitro study of its kind to clarify the shear dependence of venous wall hydraulic conductivity, though a few studies have investigated the hydraulic conductivities of endothelial cell monolayers, capillaries and arterial vessels [10, 12, 26-29]. From our experimental results, it was found that the luminal flow in the venous vessels investigated could cause a significant increase in $L_{\mathrm{p}, \mathrm{vein}}$ when compared with the case of flow absence. This finding was consistent with the studies performed on arteries, capillaries and endothelial cell monolayers by others, which indicated that flow shear could induce increases in hydraulic conductivity via a NO-dependent mechanism [10,30]. But, our results showed that the increase in hydraulic conductivity of venous segments induced by a change of WSS (from zero to a steady level of more than $0.7 \mathrm{dyn} / \mathrm{cm}^{2}$ ) was approximately $100 \%$, which was much higher than the results obtained on intact arterial vessels (e.g., the excised rabbit carotid artery [12] that exhibited only $30 \%$ increase in hydraulic conductivity when WSS elevated from 0 to $1 \mathrm{dyn} / \mathrm{cm}^{2}$ ), but was lower than those obtained on endothelial cell monolayers (e.g., exposure of cultured bovine aortic endothelial monolayers 
to a WSS of $12 \mathrm{dyn} / \mathrm{cm}^{2}$ elicited a 2.37 -fold increase in hydraulic conductivity [10]). This discrepancy might be attributed to the structural differences in the subendothelial layers of the test models. It had been documented that the subendothelial layers of blood vessels, including the intima and media, contribute most of the overall resistance to filtration flow across the vessel wall $[31,32]$. Considering that the endothelial cell monolayers have no subendothelial layer and the subendothelial layer in the artery is thicker and compacter than that of the vein, the sensitivity of the venous wall hydraulic conductivity in response to WSS should be between those of the arterial wall and the endothelial cell monolayers.

Based on the obtained hydraulic conductivity, we simulated numerically the transport of LDLs within the venous graft of an arterial bypass model. It had been documented that LDL transport, including the transport in the lumen (from the bulk blood flow to the endothelium) and the trans-endothelial transport (across the endothelium), was mainly affected by hydraulic conductivity [18]. Indeed, our numerical results revealed a significant difference in $c_{\mathrm{w}}$ between Case A (with flow and $L_{\mathrm{p} \text {,vein }}=2.33 \times 10^{-11} \mathrm{~m} / \mathrm{s} \mathrm{Pa}$ ) and Case B (with no flow of $L_{\mathrm{p}, \text { vein }}=1.16 \times 10^{-11} \mathrm{~m} / \mathrm{s} \mathrm{Pa}$ ). This finding suggests that flow could affect $L_{\mathrm{p}, \text { vein }}$, then affecting LDL deposition/accumulation within the graft wall.

In addition, our result showed that there was no evident difference in $c_{\mathrm{w}}$ between Case A and Case $C$ (in which $L_{\mathrm{p}, \text { vein }}$ was assumed to be shear dependent), indicating that the influence of shear-dependent $L_{\mathrm{p} \text {,vein }}$ on LDL transport was marginal. This seems different from some previous studies that demonstrated a significant influence of hydraulic conductivity with shear-dependent nature on LDL transport. For instance, using an idealized model of a stenosed artery, Sun et al. [19] found that when compared with the independent case, the shear-dependent $L_{\mathrm{p}}$ could lead to apparent differences in LDL concentration within the subendothelium, in which the difference could reach as high as $12 \%$. We suppose that the discrepancy between our results and others could be explained as follows. Different from the artery, hydraulic conductivity of the vein was almost independent of the flow-induced wall shear stress except for when the WSS was extremely low. Since there were very few regions in the bypass model with very low WSS, the hydraulic conductivities of the venous graft wall for Case $C$ (the shear-dependent case) had to be similar to that in Case A (the independent one).

In the present study, we also investigated the effect of stenosis severity of the host artery on LDL infiltration/accumulation within the venous graft wall. The results showed that there were some moderate differences in $c_{\mathrm{w}}$ among the cases with different stenosis in the host artery. When compared the $90 \%$ occlusion model with the $70 \%$ one, the maximum percentage difference in the $c_{\mathrm{w}}$ reaches $15 \%$. We believe that the effect of the stenosis severity on $c_{\mathrm{w}}$ is mostly caused by the luminal blood flow per se rather than the filtration rate across the graft wall because the hydraulic conductivity of the venous graft is almost constant along the venous graft.

Here, it should be mentioned that to simplify the simulation, the complex heterogeneous structure of the vessel wall was approximated by a simple homogeneous layer. In recent years, multilayer models were used to characterize LDL transport in blood vessel walls $[18,33,34]$, which could better describe the distribution of LDLs in the venous graft. One thing that should be addressed is that the hemodynamic condition can be influenced by several factors (individual geometric parameters, material parameters, 
realistic blood flow condition). Investigators have paid much more attention to these aspects. For example, Peng et al. investigated the correlation between hemodynamic parameters and individual geometric factors in the patient-specific coronary arteries, and their results showed that the increasing severity of the stenosis was associated with the increased maximum wall shear stress at the stenosis region [35]. Xiong et al. calculated the blood flow field distribution in idealized 2D models, and results showed that high pressure drop would create a pathological WSS environment for the further growth of the plaque [36]. Liu et al. investigated the hemodynamic alteration in the cerebral circulation and revealed that the structural status could provide comprehensive information about the hemodynamic alterations in the pathological circle of Wills arterial structures [37]. Zhang et al. introduced a pressure-based carotid arterial functional assessment index generated from computational fluid dynamic simulation based on digital subtracted angiography (DSA) data. Their results showed that the realistic blood condition obtained through invasive approach would remain one efficient way to study the relationship between hemodynamic disorder caused by internal carotid artery (ICA) stenosis and subsequent perfusion variations in brain [14]. Based on their investigations, it can be addressed that several significant parameters in terms of realistic geometry, artery material and flow condition would certainly influence the hemodynamic behavior, and then influence the LDL transport within the blood artery from the viewpoint of mass transport. Though this can be significant limitations for our study, our study remains a preliminary study as we focus on the correlation between the wall shear stress and hydraulic conductivity of venous endothelium, and its influence on the transport phenomenon of LDL. Further studies based on more comprehensive models and realistic blood conditions still need to be carried out to strengthen our study.

\section{Conclusion}

To probe the possibility that the blood flow condition would affect the accumulation of LDLs within the graft by influencing the hydraulic conductivity of venous graft in arterial bypass, LDL transport phenomenon in a two-dimensional bypass model with a venous graft was numerically simulated, while the deposition and accumulation of LDLs within the wall of venous graft were analyzed based on the filtration rates of the swine lateral saphenous vein under different WSS measured from the in vitro experiments. Our results indicate that the blood flow would affect the transport and accumulation of LDLs within the venous graft wall when the WSS is extremely low, as the $L_{\mathrm{p}, \text { vein }}$ can be significantly influenced by the WSS with the range of $0-0.7 \mathrm{dyn} / \mathrm{cm}^{2}$. While when WSS is above $0.7 \mathrm{dyn} / \mathrm{cm}^{2}$, the influence of shear-dependent $L_{\mathrm{p}, \text { vein }}$ on LDL transport is marginal. Since the low WSS $\left(<0.7 \mathrm{dyn} / \mathrm{cm}^{2}\right)$ areas remain few, it can be addressed that the effect of $L_{\mathrm{p}, \text { vein }}$ modulated by blood flow on LDL transport remains weak.

Abbreviations

LDLs: low-density lipoproteins; WSS: wall shear stress; BAEC: bovine aortic endothelial cell; SD: standard deviation; Re: Reynolds number; DSA: digital subtracted angiography; ICA: internal carotid artery. 


\begin{abstract}
Author details
1 Beijing Key Laboratory of Rehabilitation Technical Aids for Old-Age Disability, Key Laboratory of Technical Aids Analysis and Identification Key Laboratory of the Ministry of Civil Affairs, National Research Centre for Rehabilitation Technical Aids, Beijing 100176, China. ${ }^{2}$ Key Laboratory for Biomechanics and Mechanobiology of Ministry of Education, School of Biological Science and Medical Engineering, Beihang University, Beijing 100083, China. ${ }^{3}$ Beijing Advanced Innovation Centre for Biomedical Engineering, Beihang University, Beijing 100083, China.
\end{abstract}

\title{
Acknowledgements
}

We would like to acknowledge the funding agencies for the support of the work.

Competing interests

The authors declare that they have no competing interests.

\section{Availability of data and materials}

The datasets used and/or analyzed during the current study are available from the corresponding author on reasonable request.

\section{Consent for publication}

We consent for the publication of this work.

\section{Ethics approval and consent to participate}

Not applicable.

\section{Funding}

This work was supported by Grants-in-Aid from the National Key Research and Development Plan of China (2017YFB0702501), National Natural Science Foundation of China (Nos. 11332003, 31170904, 31570947,11602064,114212 02,11472031), and Natural Science Foundation of Jiangsu Province (BK20161366).

\section{Publisher's Note}

Springer Nature remains neutral with regard to jurisdictional claims in published maps and institutional affiliations.

Received: 11 September 2018 Accepted: 12 April 2019

Published online: 25 April 2019

\section{References}

1. Shukla N, Jeremy JY. Pathophysiology of saphenous vein graft failure: a brief overview of interventions. Curr Opin Pharmacol. 2012;12(2):114-20.

2. Raja SG, Haider Z, Ahmad M, Zaman H. Saphenous vein grafts: to use or not to use? Heart Lung Circ. 2004;13(4):403-9.

3. Ward AO, Caputo M, Angelini GD, George SJ, Zakkar M. Activation and inflammation of the venous endothelium in vein graft disease. Atherosclerosis. 2017;265:266-74.

4. Newby AC, Zaltsman AB. Molecular mechanisms in intimal hyperplasia. J Pathol. 2000;190(3):300-9.

5. Kim FY, Marhefka G, Ruggiero NJ, Adams S, Whellan DJ. Saphenous vein graft disease: review of pathophysiology, prevention, and treatment. Cardiol Rev. 2013;21(2):101-9.

6. de Vries MR, Simons KH, Jukema JW, Braun J, Quax PH. Vein graft failure: from pathophysiology to clinical outcomes. Nat Rev Cardiol. 2016;13(8):451-70.

7. Raggi P, Genest J, Giles JT, Rayner KJ, Dwivedi G, Beanlands RS, Gupta M. Role of inflammation in the pathogenesis of atherosclerosis and therapeutic interventions. Atherosclerosis. 2018;276:98-108.

8. Hu J, Xi D, Zhao J, Luo T, Liu J, Lu H, Li M, Xiong H, Guo Z. High-density lipoprotein and inflammation and its significance to atherosclerosis. Am J Med Sci. 2016;352(4):408-15.

9. Wang Z, Liu X, Kang H, Sun A, Fan Y, Deng X. Enhanced accumulation of LDLs within the venous graft wall induced by elevated filtration rate may account for its accelerated atherogenesis. Atherosclerosis. 2014;236(1):198-206.

10. Kang H, Cancel LM, Tarbell JM. Effect of shear stress on water and LDL transport through cultured endothelial cell monolayers. Atherosclerosis. 2014;233(2):682-90.

11. Sill HW, Chang YS, Artman JR, Frangos JA, Hollis TM, Tarbell JM. Shear stress increases hydraulic conductivity of cultured endothelial monolayers. Am J Physiol. 1995;268(2 Pt 2):H535-43.

12. Lever MJ, Tarbell JM, Caro CG. The effect of luminal flow in rabbit carotid artery on transmural fluid transport. Exp Physiol. 1992;77(4):553-63.

13. Armstrong J, Narracott AJ, Milton R, Galea J, Cooper GJ, Lawford PV, Hose DR, Cumberland DC, Holt CM. Development of an ex vivo model to investigate the effects of altered haemodynamics on human bypass grafts. J Med Eng Technol. 2000;24(5):183-91.

14. Zhang D, Xu P, Qiao H, Liu X, Luo L, Huang W, Zhang H, Shi C. Carotid DSA based CFD simulation in assessing the patient with asymptomatic carotid stenosis: a preliminary study. Biomed Eng Online. 2018;17(1):31.

15. Liu X, Wang L, Wang Z, Li Z, Kang H, Fan Y, Sun A, Deng X. Bioinspired helical graft with taper to enhance helical flow. J Biomech. 2016:49(15):3643-50.

16. Kedem $\mathrm{O}$, Katchalsky A. Thermodynamic analysis of the permeability of biological membranes to non-electrolytes. Biochem Biophys Acta. 1958;27(2):229-46.

17. Sun N, Wood NB, Hughes AD, Thom SA, Xu XY. Effects of transmural pressure and wall shear stress on LDL accumulation in the arterial wall: a numerical study using a multilayered model. Am J Physiol Heart Circ Physiol. 2007;292(6):H3148-57. 
18. Liu X, Fan Y, Deng X. Effect of the endothelial glycocalyx layer on arterial LDL transport under normal and high pressure. J Theor Biol. 2011;283(1):71-81.

19. Sun N, Wood NB, Hughes AD, Thom SA, Xu XY. Fluid-wall modelling of mass transfer in an axisymmetric stenosis: effects of shear-dependent transport properties. Ann Biomed Eng. 2006;34(7):1119-28.

20. Katz MA. New formulation of water and macromolecular flux which corrects for non-ideality: theory and derivation, predictions, and experimental results. J Theor Biol. 1985;112(2):369-401.

21. Tarbell JM, Lever MJ, Caro CG. The effect of varying albumin concentration of the hydraulic conductivity of the rabbit common carotid artery. Microvasc Res. 1988;35(2):204-20.

22. Wang $\mathrm{S}$, Vafai K. Analysis of low density lipoprotein (LDL) transport within a curved artery. Ann Biomed Eng. 2015;43(7):1571-84.

23. Karner G, Perktold K, Zehentner HP. Computational modeling of macromolecule transport in the arterial wall. Comput Methods Biomech Biomed. 2001;4(6):491-504.

24. Meyer G, Merval R, Tedgui A. Effects of pressure-induced stretch and convection on low-density lipoprotein and albumin uptake in the rabbit aortic wall. Circ Res. 1996;79(3):532-40.

25. Sun N, Wood NB, Hughes AD, Thom SA, Xu XY. Influence of pulsatile flow on LDL transport in the arterial wall. Ann Biomed Eng. 2007;35(10):1782-90.

26. Kim MH, Harris NR, Tarbell JM. Regulation of capillary hydraulic conductivity in response to an acute change in shear. Am J Physiol Heart Circ Physiol. 2005;289(5):H2126-35.

27. Lakshminarayanan S, Gardner TW, Tarbell JM. Effect of shear stress on the hydraulic conductivity of cultured bovine retinal microvascular endothelial cell monolayers. Curr Eye Res. 2000;21(6):944-51.

28. Lopez-Quintero SV, Amaya R, Pahakis M, Tarbell JM. The endothelial glycocalyx mediates shear-induced changes in hydraulic conductivity. Am J Physiol Heart Circ Physiol. 2009:296(5):H1451-6.

29. Lopez-Quintero SV, Ji XY, Antonetti DA, Tarbell JM. A three-pore model describes transport properties of bovine retinal endothelial cells in normal and elevated glucose. Investig Ophthalmol Vis Sci. 2011;52(2):1171-80.

30. Chang YS, Yaccino JA, Lakshminarayanan S, Frangos JA, Tarbell JM. Shear-induced increase in hydraulic conductivity in endothelial cells is mediated by a nitric oxide-dependent mechanism. Arterioscler Thromb Vasc Biol. 2000;20(1):35-42.

31. Dabagh M, Jalali P, Tarbell JM. The transport of LDL across the deformable arterial wall: the effect of endothelial cell turnover and intimal deformation under hypertension. Am J Physiol Heart Circ Physiol. 2009;297(3):H983-96.

32. Tedgui A, Lever MJ. Filtration through damaged and undamaged rabbit thoracic aorta. Am J Physiol. 1984;247(5 Pt 2):H784-91.

33. Yang N, Vafai K. Modeling of low-density lipoprotein (LDL) transport in the artery-effects of hypertension. Int J Heat Mass Transf. 2006:49(5-6):850-67.

34. Kenjeres S, de Loor A. Modelling and simulation of low-density lipoprotein transport through multilayered wall of an anatomically realistic carotid artery bifurcation. J R Soc Interface. 2014;11(91):20130941.

35. Peng C, Wang X, Xian Z, Liu X, Huang W, Xu P, Wang J. The impact of the geometric characteristics on the hemodynamics in the stenotic coronary artery. PLoS ONE. 2016;11(6):e0157490.

36. Xiong H, Liu X, Tian X, Pu L, Zhang H, Lu M, Huang W, Zhang YT. A numerical study of the effect of varied blood pressure on the stability of carotid atherosclerotic plaque. Biomed Eng online. 2014;13:152.

37. Liu X, Gao Z, Xiong H, Ghista D, Ren L, Zhang H, Wu W, Huang W, Hau WK. Three-dimensional hemodynamics analysis of the circle of Willis in the patient-specific nonintegral arterial structures. Biomech Model Mechanobiol. 2016;15(6):1439-56.

- fast, convenient online submission

- thorough peer review by experienced researchers in your field

- rapid publication on acceptance

- support for research data, including large and complex data types

- gold Open Access which fosters wider collaboration and increased citations

- maximum visibility for your research: over $100 \mathrm{M}$ website views per year

At BMC, research is always in progress.

Learn more biomedcentral.com/submissions 